\title{
Efficacy and safety of dutasteride compared with finasteride in treating males with benign prostatic hyperplasia: A meta-analysis of randomized controlled trials
}

\author{
ZHONGBAO ZHOU ${ }^{1,2^{*}}$, YUANSHAN CUI ${ }^{2,3 *},{\text { JITAO } \mathrm{WU}^{2} \text { and HAIRONG JIN }}^{2}$ \\ ${ }^{1}$ School of Clinical Medicine, Binzhou Medical University, Yantai, Shandong 264000; \\ ${ }^{2}$ Department of Urology, The Affiliated Yantai Yuhuangding Hospital of Qingdao University, Yantai, Shandong 264000; \\ ${ }^{3}$ Department of Urology, Beijing TianTan Hospital, Capital Medical University, Beijing 100070, P.R. China
}

Received August 21, 2019; Accepted January 30, 2020

DOI: $10.3892 /$ etm.2020.8851

\begin{abstract}
The present study was an updated meta-analysis that aimed to confirm the efficacy and safety of dutasteride $(0.5 \mathrm{mg})$ and finasteride $(5 \mathrm{mg})$ in treating males with benign prostatic hyperplasia (BPH) over a treatment period of at least 6 months. Randomized controlled trials were retrieved using the MEDLINE, EMBASE and the Cochrane controlled trials register databases. The references of the associated articles were also searched. A systematic review was performed by using the preferred reporting items for systematic reviews and meta-analyses. The data were analyzed with RevMan v5.3.0. A total of six articles including 2,041 participants were studied. The analysis demonstrated a significantly greater decrease in international prostate symptom score [IPSS; mean difference (MD), $-0.86 ; 95 \% \mathrm{CI},-1.62$ to $-0.11 ; \mathrm{P}=0.02]$ and prostate-specific antigen (PSA; MD, -0.13 ; 95\% CI, -0.26 to $-0.01 ; \mathrm{P}=0.03$ ) in the dutasteride group compared with that in the finasteride group, whereas no significant differences were observed in prostate volume ( $\mathrm{PV} ; \mathrm{P}=0.64)$, maximum urine flow rate $(\mathrm{Qmax} ; \mathrm{P}=0.29)$ and post-void residual volume (PVRV; $\mathrm{P}=0.14$ ). With regard to safety assessment, including
\end{abstract}

Correspondence to: Dr Hairong Jin, Department of Urology, The Affiliated Yantai Yuhuangding Hospital of Qingdao University, 20 East Yuhuangding Road, Yantai, Shandong 264000, P.R. China E-mail: m15275525316@163.com

*Contributed equally

Abbreviations: $\mathrm{BPH}$, benign prostatic hyperplasia; DHT, dihydrotestosterone; 5ARI, 5 $\alpha$-reductase inhibitors; RCT, randomized controlled trial; IPSS, International Prostate Symptom Score; PV, prostate volume; Qmax, maximum urine flow rate; PVRV, post-void residual volume; PSA, prostate-specific antigen; AE, adverse event; MD, mean difference; OR, odds ratio; LUTS, lower urinary tract symptoms

Key words: benign prostatic hyperplasia, dutasteride, finasteride, meta-analysis, randomized controlled trials any adverse event $(\mathrm{P}=0.66)$, decreased libido $(\mathrm{P}=0.39)$ and impotence $(\mathrm{P}=0.17)$, there was no significant difference between dutasteride and finasteride. In conclusion, in patients with BPH, dutasteride produced a greater decrease in IPSS and PSA compared with finasteride, whereas no significant differences were identified in PV, Qmax and PVRV. The two drugs appeared to have similar rates of adverse effects, particularly with regard to sexual dysfunction.

\section{Introduction}

Benign prostatic hyperplasia ( $\mathrm{BPH})$ is a primary etiology of dysplasia of the prostate that occurs mainly in the elderly and is characterized by nonmalignant hypertrophy of the prostate gland due to unrestricted proliferation of epithelial and smooth muscle cells positioned in the transition region of the prostate gland encircling the urethra $(1,2)$. Patients with BPH may suffer from frequent micturition, interrupted urine flow, sense of incomplete bladder emptying and a high risk of acute urinary retention, which impact the quality of life $(3,4)$.

Changes of androgen levels are considered to be a crucial factor for the development of prostate growth with age (5). Dihydrotestosterone (DHT), an important constituent among the androgens, may be synthesized from testosterone by $5 \alpha$-reductase (5AR) in the prostate gland (6). With the reduction in testosterone levels, the excessive expression of DHT triggers the proliferation of prostate epithelial and mesenchymal cells, leading to the development of $\mathrm{BPH}(7,8)$. To inhibit this process, 5AR inhibitors (5ARI) are administered to lower the serum concentration of DHT, controlling the normal growth of the prostate itself and the progression of BPH (9). Two 5ARIs are available: finasteride and dutasteride. Finasteride is a selective inhibitor of type 2 5ARI, whereas dutasteride inhibits type 1 and 2 5ARI $(10,11)$. Dutasteride, due to the additional target, induces a theoretically greater reduction in DHT and improvement in clinical presentation compared with finasteride. However, two previous meta-analyses comparing the efficacy of the two drugs limited their search due to a lack of standard analysis of clinical data on various aspects and provided ambiguous results on whether finasteride and dutasteride exhibited any clinically significant differences $(12,13)$. 
The present study was an updated meta-analysis aiming to compare the efficacy and safety of $0.5 \mathrm{mg}$ dutasteride and $5 \mathrm{mg}$ finasteride (the doses widely used in the clinic) in treating $\mathrm{BPH}$ during a treatment period of at least 6 months.

\section{Materials and methods}

Protocol. The present systematic review of randomized controlled trials (RCTs) was performed using the Preferred Reporting Items for Systematic Reviews and Meta-analyses checklist (14).

Information sources and literature search. The MEDLINE (January 1992 to December 2018), EMBASE (January 1995 to December 2018) and the Cochrane controlled trials register databases were searched to compare the effects of dutasteride and finasteride in BPH treatment. The following search terms were used: ['finasteride' (MeSH terms) OR 'finasteride' (all fields)] AND ['dutasteride' (MeSH terms) OR 'dutasteride' (all fields)] AND ['prostatic hyperplasia' (MeSH terms) OR ['prostatic' (all fields) AND 'hyperplasia' (all fields)] OR 'prostatic hyperplasia' (all fields) OR ['benign' (all fields) AND 'prostatic' (all fields) AND 'hyperplasia' (all fields)] OR 'benign prostatic hyperplasia' (all fields). All publications were browsed independently by all authors. The study was limited to published research with no restrictions on language. Reviews and summaries presented at meetings were excluded. Authors were contacted to obtain further information when necessary. The references of relevant publications were also searched.

Inclusion criteria and trial selection. The inclusion criteria for the publications were as follows: i) Dutasteride vs. finasteride in treating BPH were evaluated; ii) the content and associated data of the publication were available; iii) the data provided by the publication were valid and valuable, including the overall number of events and valuable results for each indicator; iv) the design of the study was that of an $\mathrm{RCT}$; v) the treatment duration was $\geq 6$ months. If the results of a trial were published by two or more studies, the latest publication was selected. However, if a group of patients was included in two or more studies, each of the studies may have been analyzed in the present study. It was also checked whether the cohorts overlapped and no overlaps were found. The flow diagram of the study selection and elimination is presented in Fig. 1.

Quality assessment methods. The quality of the studies selected was evaluated using the Jadad scale (15). In addition, a number of strategies of assessment were applied to determine the quality of individual studies, including the distribution method of participants, blinding regarding the distribution process, double-blinding and the number of patients lost at follow-up. Subsequently, individual studies were assessed following the principles derived from the Cochrane Handbook for Systematic Reviews of Interventions v5.10 (16). Each publication was evaluated and three quality classification standards were assigned: a) When a study satisfied the majority of the quality criteria, it was considered to have a low probability of bias; b) when the quality criteria were partially satisfied or unclear, the study was considered to have a moderate probability of bias; and c) when the criteria were barely satisfied, the study was considered to have a high probability of bias. All authors participated in the quality assessment of the RCTs retrieved and eventually agreed with the results of the assessment. All reviewers independently assessed whether each study satisfied the criteria and extracted the data from the selected studies. Any discrepancies were recorded, discussed and settled by negotiation.

Data extraction. Two authors independently collected data from the publications based on predetermined criteria. The following usable data were extracted from the studies included: i) Publication year; ii) the first author's name; iii) details on patient treatment; iv) number of participants; and v) international prostate symptom score (IPSS), prostate volume (PV), maximum urine flow rate (Qmax), post-void residual volume (PVRV), prostate-specific antigen (PSA), adverse events (AEs), decreased libido and impotence. These results were considered clinically significant as their impact on patients was measurable. No ethical approval was required for this study.

The primary outcomes were IPSS and PSA. High IPSS indicated more severe symptoms. Data on secondary outcomes, including PV, Qmax and PVRV were reported with acceptable consistency among the studies to allow for analysis. In addition, the number of any AEs, decreased libido and impotence were also analyzed between the two groups of patients receiving different treatments.

Statistical and meta-analysis. The analysis of the study was performed using RevMan version 5.3.0 (Cochrane Collaboration) (16). Fixed or random-effects models were used to evaluate the publications. The mean difference (MD) was used to analyze continuous data and the odds ratio (OR) was calculated for dichotomous results with the corresponding 95\% CI (17). The results of analysis showed that the P-value $>0.05$ for the $\mathrm{I}^{2}$ statistic, the study was considered to be homogeneous and the fixed-effects model was used for the analysis. Inconsistency was analyzed by the $\mathrm{I}^{2}$ statistic, which reflected the proportion of heterogeneity across trials. A random-effects model was used for studies with an $\mathrm{I}^{2}$ value $>50 \%$, suggesting significant heterogeneity. $\mathrm{P}<0.05$ was considered to indicate a statistically significant difference.

\section{Results}

Study selection process, search results and characteristics of the trials. A total of 240 publications were initially retrieved from the databases. Scrutinizing their abstracts and titles resulted in the exclusion of 204 publications. Among the remaining 36 studies, 29 were excluded due to a lack of effective data. In addition, two publications described the same data and one of these publications was excluded. Finally, six publications describing six RCTs (18-23) were included in the present study to compare the effects of dutasteride and finasteride in treating $\mathrm{BPH}$ during a treatment period of $\geq 6$ months. The basic features of the six studies are presented in Table I.

Risk of bias in the studies. All studies included in the meta-analysis were RCTs; however, not all of the studies 
240 articles were identified including:

MEDLINE: 185 articles

EMBASE: 48 articles

Cochrane Controlled Trials Register: 7 articles

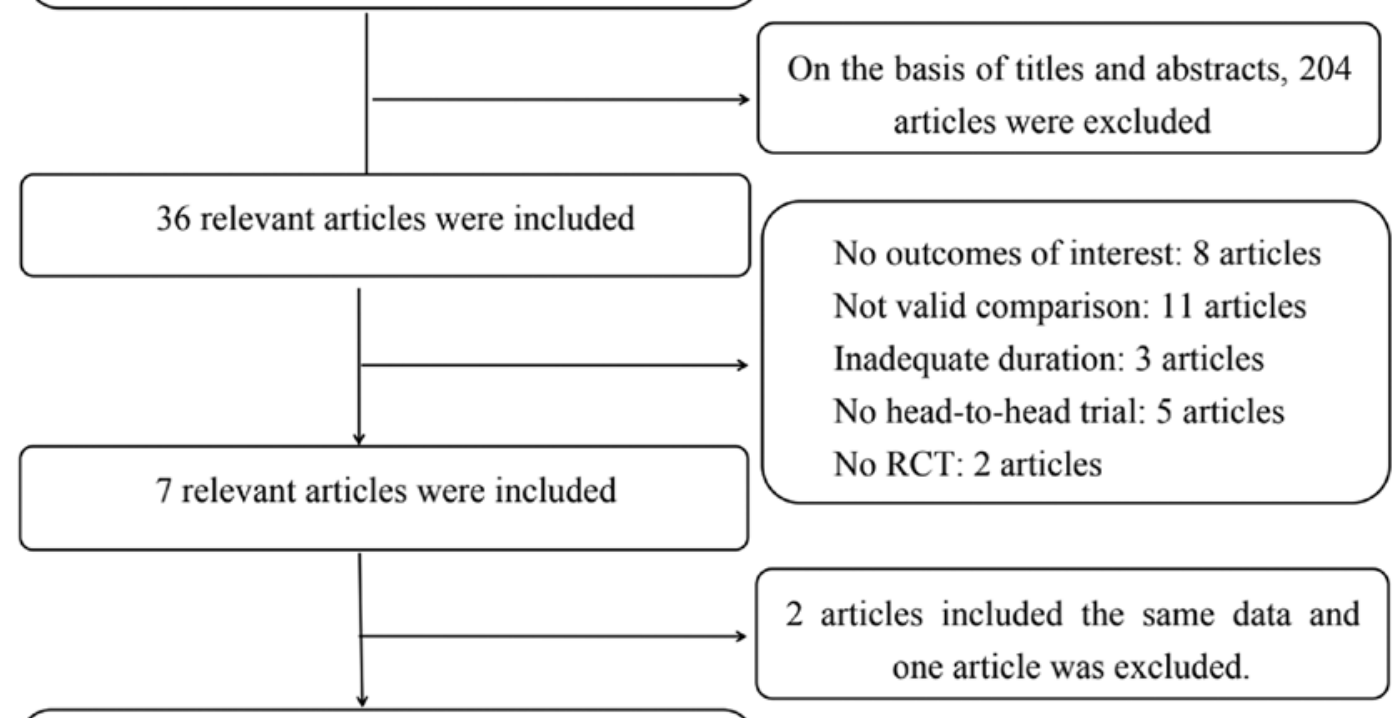

6 studies on 6 RCTs comparing dutasteride

with finasteride for BPH over a treatment

period of at least 6 months were finally

included in the meta-analysis.

Figure 1. Flowchart of the study selection process. RCT, randomized controlled trial; BPH, benign prostatic hyperplasia.

specified the protocol of randomization. All studies included an appropriate number of participants and one study included an intention-to-treat analysis (21) (Table II). In addition, two studies used a combined medication regimen with $\alpha$-blockers $(19,20)$ and one study described a post-operative medication regimen (23). However, in these studies, the specific methods of blinding were not explicitly explained and their grade were rated as 'B' based on the Cochrane handbook. The plot was highly symmetrical and six squares were contained in the accepted region of the funnel plot, with no evidence of bias being found (Fig. 2). The bias of quality assessment are presented in Fig. 3.

\section{Efficacy}

IPSS. A total of five RCTs including 1,929 patients were used for the IPSS analysis. High heterogeneity among the trials was identified $\left(\mathrm{P}<0.00001 ; \mathrm{I}^{2}=88 \%\right)$. The forest plots indicated a significantly greater decrease in IPSS in the dutasteride group compared with that in the finasteride group (MD, -0.86; 95\% CI, -1.62 to $-0.11 ; \mathrm{P}=0.02$; Fig. $4 \mathrm{~A})$.

$P V$. A total of five RCTs including 1,929 patients were used for the analysis of the change of PV. High heterogeneity was identified among the studies in the forest plots $\left(\mathrm{P}<0.0001 ; \mathrm{I}^{2}=83 \%\right)$. Dutasteride was not significantly more effective compared with finasteride in reducing the PV (MD, $-0.40 ; 95 \%$ CI, -2.11 to $1.30 ; \mathrm{P}=0.64$; Fig. $4 \mathrm{~B})$.
Qmax. A total of three RCTs including 1,747 patients contained data on Qmax. Low risk of heterogeneity was identified among the studies $\left(\mathrm{P}=0.23 ; \mathrm{I}^{2}=31 \%\right)$. The fixed-effects model demonstrated no significant differences between dutasteride and finasteride in improving the Qmax (MD, 0.16; 95\% CI, -0.13 to $0.45 ; \mathrm{P}=0.29$; Fig. $4 \mathrm{C}$ ).

$P V R V$. A total of three RCTs including 222 patients were used for the analysis of PVRV. The results of the heterogeneity test were $\mathrm{P}=0.58$ and $\mathrm{I}^{2}=0 \%$. The fixed-effects model did not identify any statistically significant differences between dutasteride and finasteride in reducing PVRV (MD, $-1.92 ; 95 \% \mathrm{CI}$, -4.45 to 0.61 ; $\mathrm{P}=0.14$; Fig. $5 \mathrm{~A}$ ).

PSA. A total of five RCTs including 1,929 patients contained data on PSA. Heterogeneity was identified among the studies $\left(\mathrm{P}=0.0008 ; \mathrm{I}^{2}=79 \%\right)$. Dutasteride was significantly more effective compared with finasteride in lowering PSA (MD, -0.13; 95\% CI, -0.26 to -0.01 ; $\mathrm{P}=0.03$; Fig. $5 \mathrm{~B})$.

\section{Safety}

Any AE. A total of five RCTs with a sample of 1,964 participants evaluated the severity of any AE. The results of the heterogeneity test were $\mathrm{P}=0.84$ and $\mathrm{I}^{2}=0 \%$. The meta-analysis identified no significant differences between the dutasteride and finasteride groups in the severity of any $\mathrm{AE}$ across the five studies (OR, 0.96; 95\% CI, 0.80 to 1.15 ; $\mathrm{P}=0.66$; Fig. 6A). 


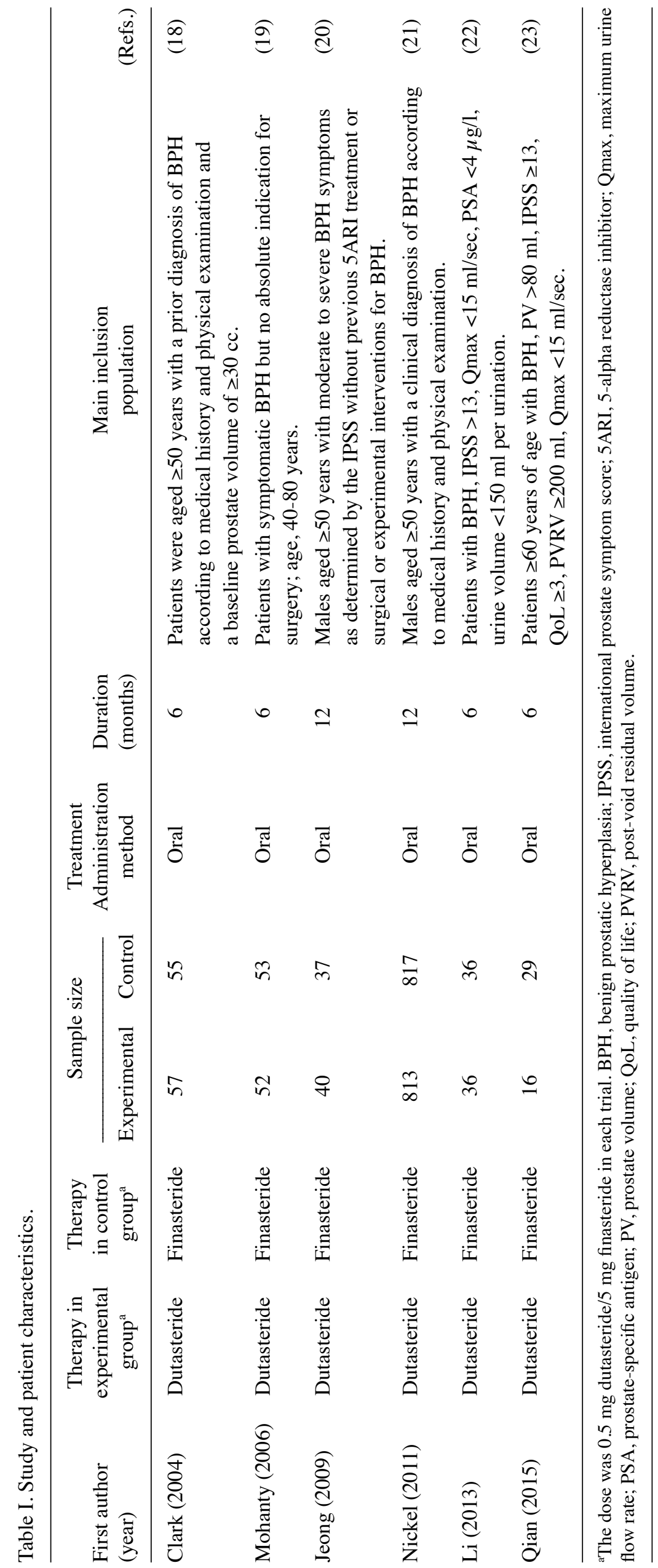


Table II. Quality assessment of individual studies.

\begin{tabular}{|c|c|c|c|c|c|c|c|c|c|}
\hline $\begin{array}{l}\text { First author } \\
\text { (year) }\end{array}$ & $\begin{array}{l}\text { Allocation } \\
\text { sequence } \\
\text { generation }\end{array}$ & $\begin{array}{l}\text { Allocation } \\
\text { concealment }\end{array}$ & Blinding & $\begin{array}{l}\text { Loss to } \\
\text { follow-up }\end{array}$ & $\begin{array}{c}\text { Calculation } \\
\text { of sample } \\
\text { size }\end{array}$ & $\begin{array}{l}\text { Statistical } \\
\text { analysis }\end{array}$ & $\begin{array}{l}\text { Level of } \\
\text { quality }\end{array}$ & $\begin{array}{c}\text { ITT } \\
\text { analysis }\end{array}$ & (Refs.) \\
\hline Clark (2004) & A & A & A & 2 & Yes & $\begin{array}{l}\text { Fisher's exact test; } \\
\text { Student's t-test }\end{array}$ & A & No & (18) \\
\hline $\begin{array}{l}\text { Mohanty } \\
(2006)\end{array}$ & A & A & B & 5 & Yes & $\begin{array}{c}\text { ANCOVA; } \\
\text { Student's t-test }\end{array}$ & A & No & (19) \\
\hline Jeong (2009) & A & A & B & 0 & Yes & $\begin{array}{c}\text { ANCOVA; } \\
\text { Student's t-test }\end{array}$ & A & No & (20) \\
\hline Nickel (2011) & A & A & A & 72 & Yes & $\begin{array}{l}\text { Log-transformed } \\
\text { linear model }\end{array}$ & A & Yes & (21) \\
\hline Li (2013) & A & A & B & 0 & Yes & $\begin{array}{l}\text { Student's t-test; } \\
\chi^{2} \text { test }\end{array}$ & A & No & (22) \\
\hline Qian (2015) & A & A & B & 8 & Yes & $\begin{array}{c}\text { Student's t-test; } \\
\text { Fisher's exact test; } \\
\chi^{2} \text { test }\end{array}$ & A & No & (23) \\
\hline
\end{tabular}

$\mathrm{A}$, almost all quality criteria met (adequate): Low risk of bias; B, one or more quality criteria met (moderate): Moderate risk of bias; $\mathrm{C}$, one or more criteria not met (inadequate or not used): High risk of bias; ITT, intention-to-treat; ANCOVA, analysis of covariance.

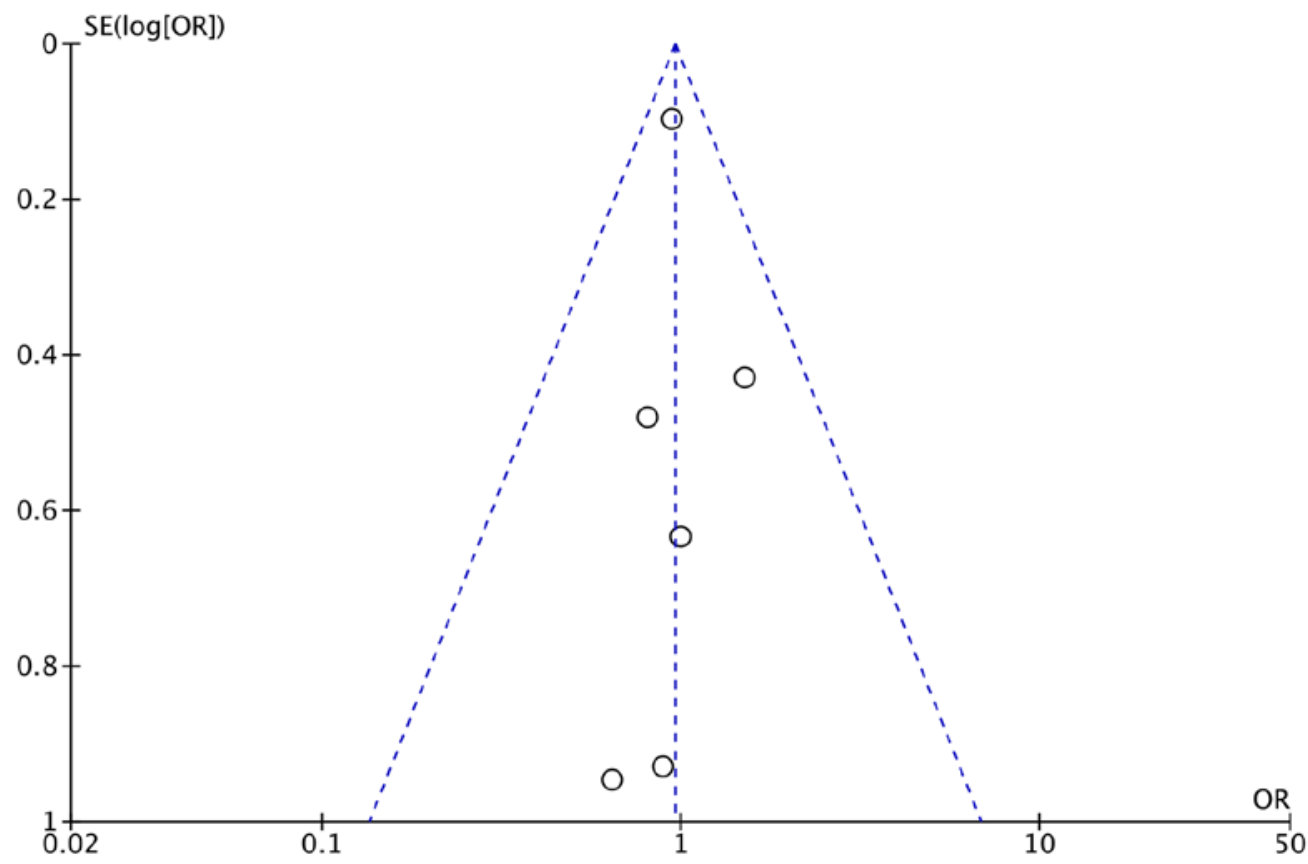

Figure 2. Funnel plot of the studies included in the present meta-analysis. SE, standard error; OR, odds ratio.

Decreased libido. A total of four RCTs with a sample of 1,919 participants assessed the severity of decreased libido. The results of the heterogeneity test were $\mathrm{P}=0.93$ and $\mathrm{I}^{2}=0 \%$. The fixed-effects model identified no significant differences between the dutasteride and finasteride groups in the severity of decreased libido among the four studies (OR, 0.85; 95\% CI, 0.58 to 1.24 ; $\mathrm{P}=0.39$; Fig. $6 \mathrm{~B}$ ).

Impotence. A total of four RCTs with a suitable sample of 1,919 participants analyzed the severity of impotence. The results of the heterogeneity test were $\mathrm{P}=0.82$ and $\mathrm{I}^{2}=0 \%$. The fixed-effects model identified no statistically significant differences between the dutasteride and finasteride groups in the severity of impotence among the four studies (OR, 0.79; $95 \% \mathrm{CI}, 0.57$ to $1.10 ; \mathrm{P}=0.17$; Fig. $6 \mathrm{C}$ ).

\section{Discussion}

$\mathrm{BPH}$ is the most common benign disease among males aged $>50$ years and its occurrence rate increases with age. BPH mani- 
Random sequence generation (selection bias)

Allocation concealment (selection bias)

Blinding of participants and personnel (performance bias)

Blinding of outcome assessment (detection bias)

Incomplete outcome data (attrition bias)

Selective reporting (reporting bias)

Other bias

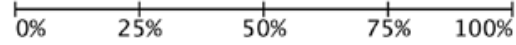

Low risk of bias

Unclear risk of bias

High risk of bias

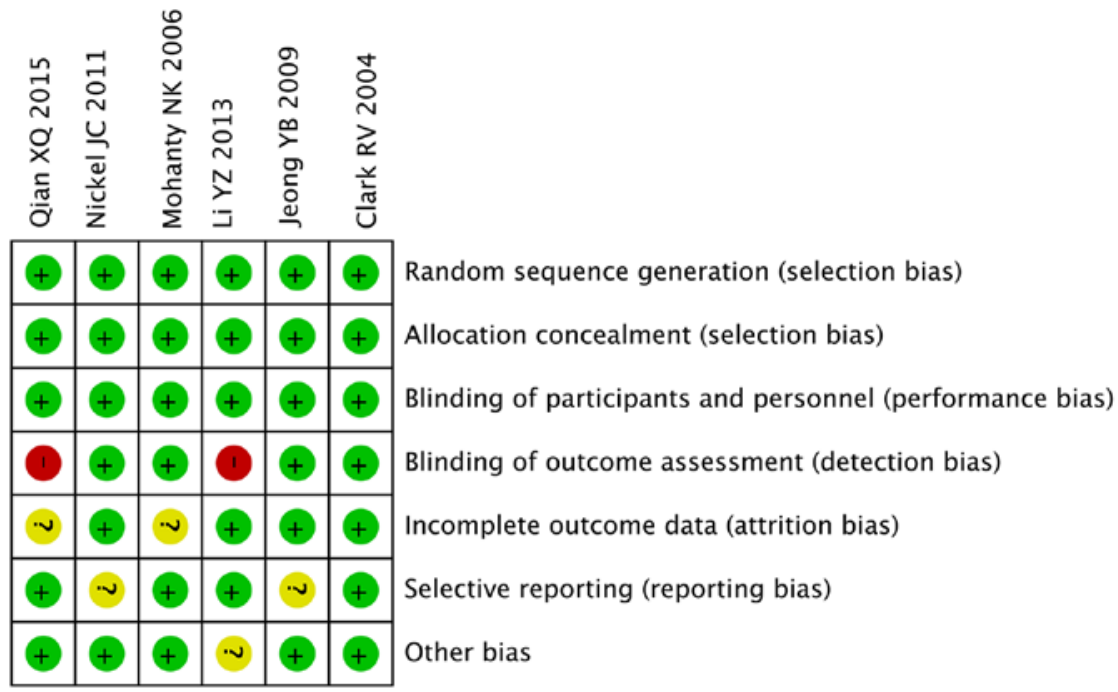

Figure 3. Risk of bias summary and graph.

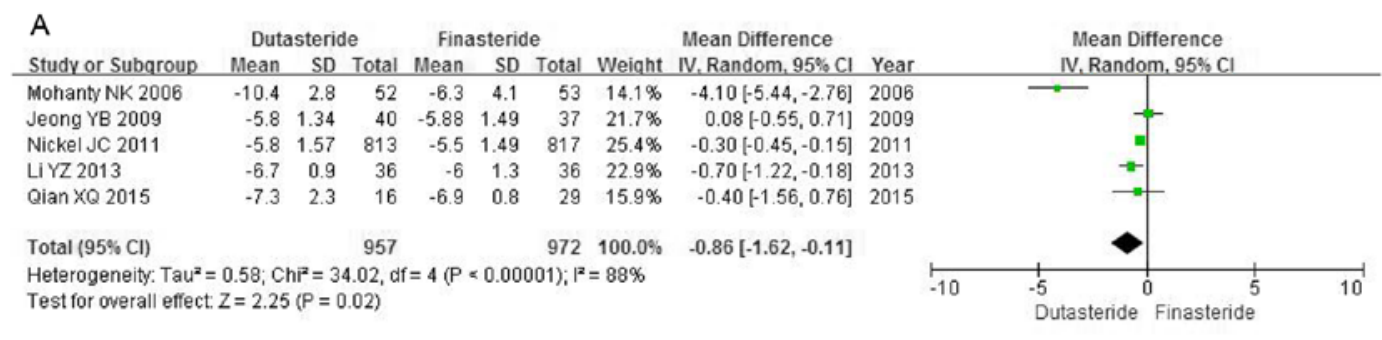

\section{в

\begin{tabular}{|c|c|c|c|c|c|c|c|c|c|}
\hline \multirow[b]{2}{*}{ Studv or Subqroup } & \multicolumn{3}{|c|}{ Dutasteride } & \multicolumn{3}{|c|}{ Finasteride } & \multicolumn{3}{|c|}{ Mean Difference } \\
\hline & Mean & SD & Total & Mean & SD & Total & Weight & IV, Random, $95 \% \mathrm{Cl}$ & Ye \\
\hline Mohanty NK 2006 & -6 & 2.6 & 52 & -8.9 & 6.7 & 53 & $20.5 \%$ & $2.90[0.96,4.84]$ & \\
\hline Jeong YB 2009 & -10.25 & 4 & 40 & -9.76 & 1.72 & 37 & $23.7 \%$ & $-0.49[-1.85,0.87]$ & \\
\hline Nickel JC 2011 & -14.3 & 6.9 & 813 & -13.9 & 9.37 & 817 & $26.3 \%$ & $-0.40[-1.20,0.40]$ & \\
\hline LIYZ 2013 & -8.1 & 1.6 & 36 & -5.2 & 3.9 & 36 & $23.6 \%$ & $-2.90[-4.28,-1.52]$ & \\
\hline Qian XQ 2015 & -45.7 & 10.5 & 16 & -44.1 & 9.8 & 29 & $5.9 \%$ & $-1.60[-7.86,4.66]$ & \\
\hline Total $(95 \% \mathrm{Cl})$ & & & 957 & & & 972 & $100.0 \%$ & $-0.40[-2.11,1.30]$ & \\
\hline
\end{tabular} \\ Heterogeneity. Tau $^{2}=2.73 ; \mathrm{Chi}^{2}=23.61, \mathrm{df}=4(\mathrm{P}<0.0001) ; \mathrm{I}^{2}=83 \%$}

Test for overall effect $Z=0.46(P=0.54)$
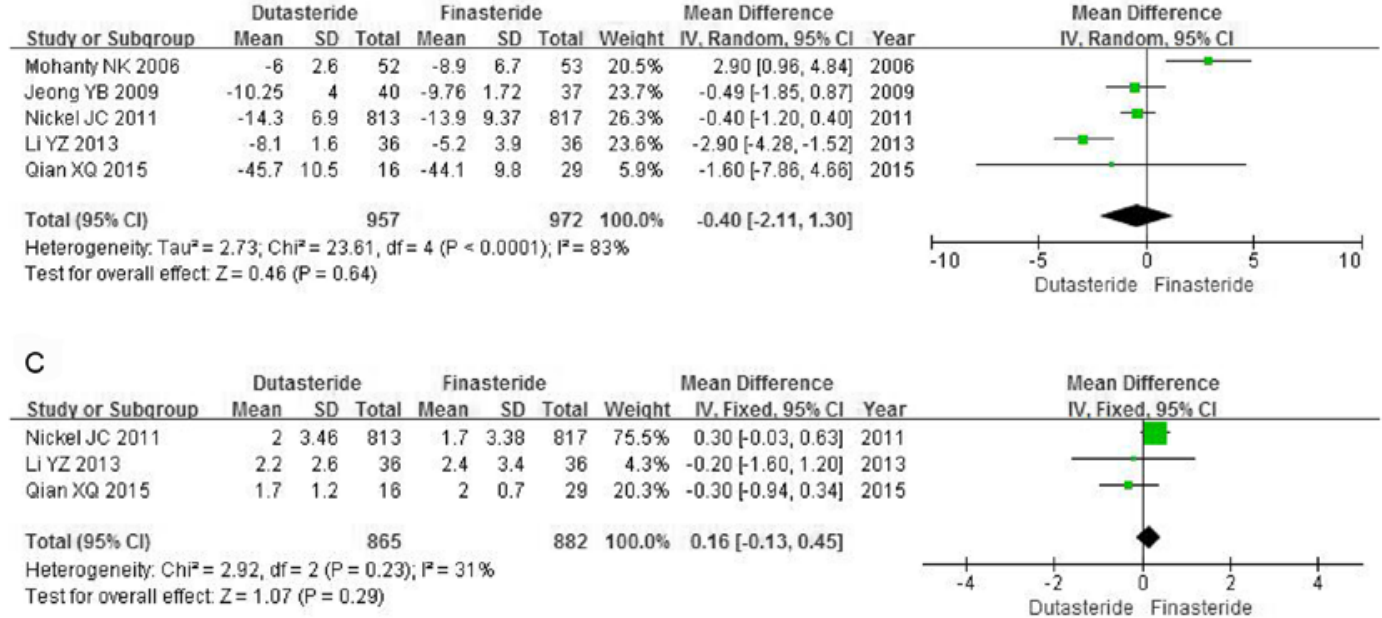

Figure 4. Forest plots indicating changes in (A) international prostate symptom score, (B) prostate volume and (C) maximum urine flow rate. SD, standard deviation; IV, inverse variance; df, degrees of freedom. 


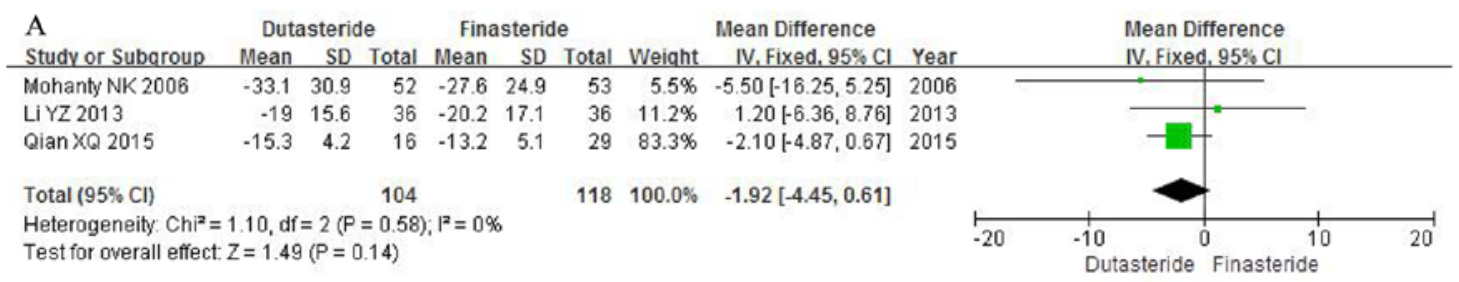

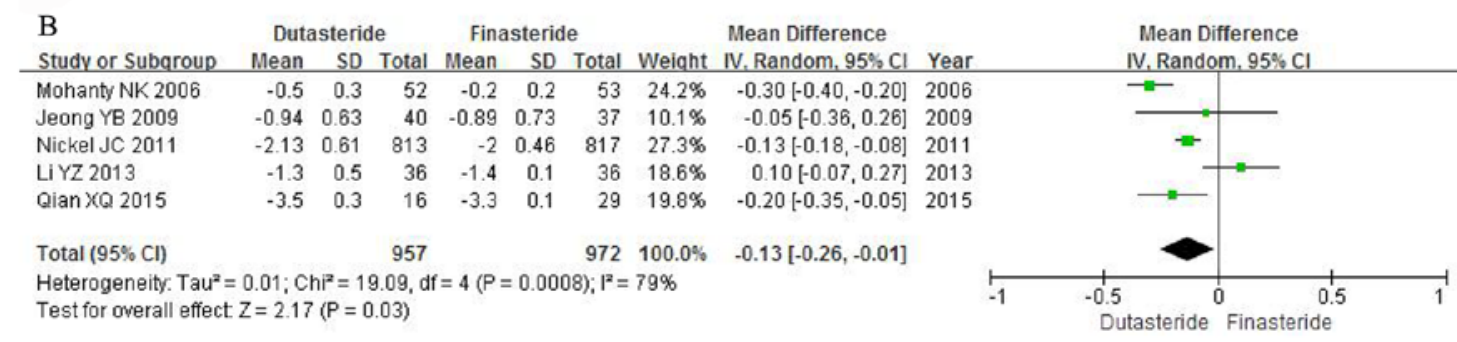

Figure 5. Forest plots indicating changes in (A) post-void residual volume and (B) prostate-specific antigen. SD, standard deviation; IV, inverse variance; df, degrees of freedom.

\begin{tabular}{|c|c|c|c|c|c|c|c|}
\hline A & Dutastr & & Finaste & ride & & Odds Ratio & \\
\hline Study or Subqroup & Events & Total & Events & Total & Weight & M-H. Fixed, $95 \% \mathrm{Cl}$ & Year \\
\hline Clark RV 2004 & 44 & 57 & 38 & 55 & $3.8 \%$ & $1.51[0.65,3.52]$ & 2004 \\
\hline Mohanty NK 2006 & 10 & 52 & 12 & 53 & $4.1 \%$ & $0.81[0.32,2.09]$ & 2006 \\
\hline Nickel JC 2011 & 396 & 813 & 409 & 817 & $89.8 \%$ & $0.95[0.78,1.15]$ & 2011 \\
\hline LiYZ 2013 & 2 & 36 & 3 & 36 & $1.2 \%$ & $0.65[0.10,4.12]$ & 2013 \\
\hline Qian XQ 2015 & 2 & 16 & 4 & 29 & $1.1 \%$ & $0.89[0.14,5.51]$ & 2015 \\
\hline Total $(95 \%$ Cl) & & 974 & & 990 & $100.0 \%$ & $0.96[0.80,1.15]$ & \\
\hline Total events & 454 & & 466 & & & & \\
\hline Heterogeneity: $\mathrm{Chi}^{2}$ & $44, d f=$ & $4(P=$ & $0.84) ; 1^{2}=$ & & & & \\
\hline
\end{tabular}

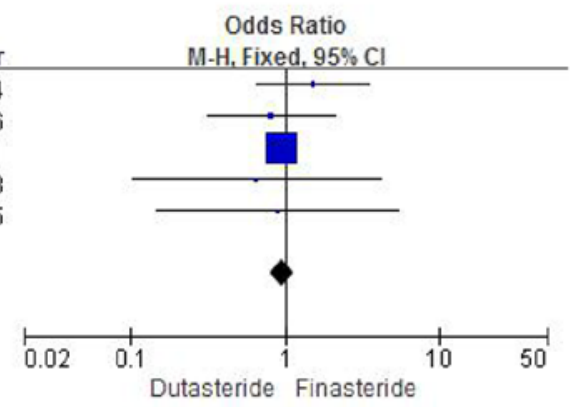

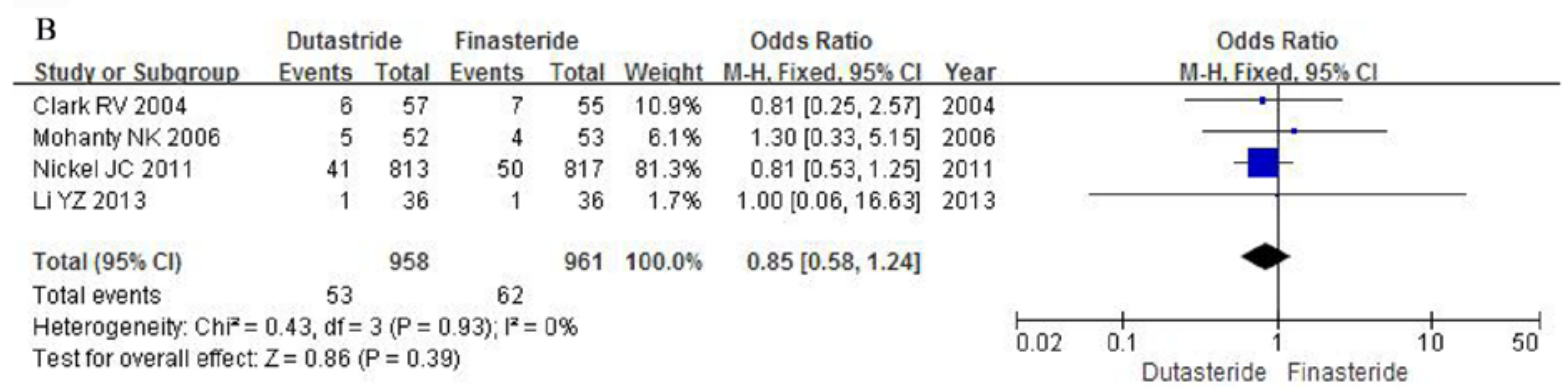

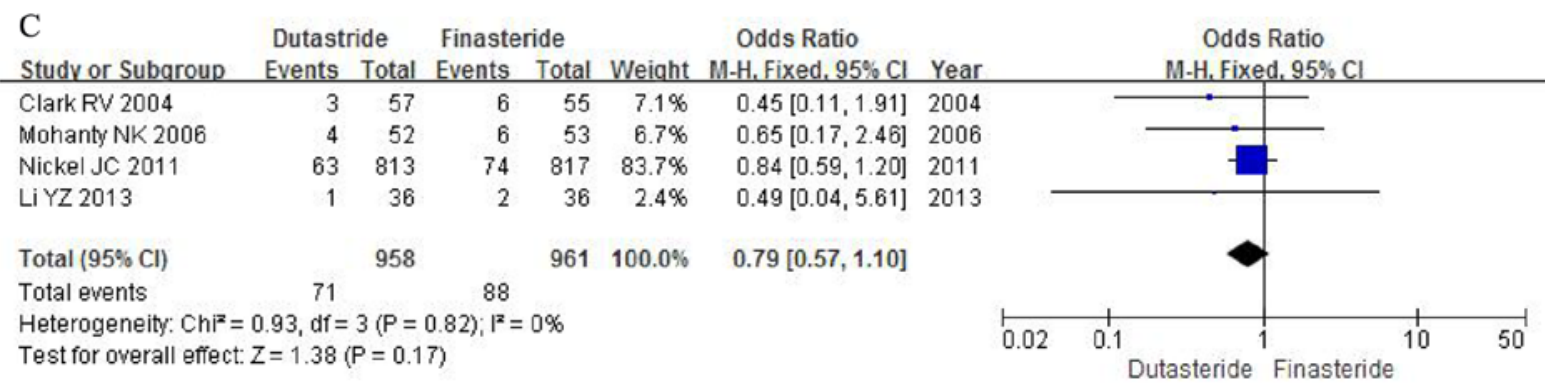

Figure 6. Forest plots indicating changes in (A) any adverse event, (B) decreased libido and (C) impotence. M-H, Mantel-Haenszel; df, degrees of freedom.

fests as lower urinary tract symptoms (LUTS), increased total PV, decreased peak urinary flow and increased IPSS $(24,25)$. Previously identified pathogenetic mechanisms suggest that androgenic disorders are the vital factors for the progress of $\mathrm{BPH}$, resulting in abnormal prostate gland enlargement, compression of the prostatic part of the urethra and changes in the urinary tract $(5,26)$. Without treatment, the quality of life and sexual function of the patients severely declines (27). 
Pharmacological treatments are generally reserved for patients with moderate or severe $\mathrm{BPH}$, as it helps to alleviate the symptoms of bladder outlet obstruction and reduces pre-operative-to-post-operative risk of acute urinary retention. Finasteride and dutasteride, which are types of 5ARIs, are currently most frequently prescribed to improve the unpleasant symptoms $(10,28)$. The therapeutic effect of monotherapy using the two drugs was confirmed in previous clinical studies and a systematic review; however, growing concern has arisen regarding the AEs of the drugs, particularly on sexual function (mainly decreased libido and impotence) (29). To address the limitations of previous analyses, the present study re-searched the literature, extracted and analyzed the data, systematically explained the advantages and disadvantages of the two drugs and provided novel results.

The present updated meta-analysis was performed using six studies including 2,041 participants to compare the efficacy and safety of dutasteride $(0.5 \mathrm{mg} /$ day $)$ and finasteride $(5 \mathrm{mg} /$ day $)$ in treating BPH for $\geq 6$ months. The analysis demonstrated a significantly greater decrease in IPSS and PSA in the dutasteride group compared with that in the finasteride group, whereas no significant differences were identified in PV, Qmax and PVRV. Of note, five RCTs evaluating the changes of IPSS as a subjective measurement, which required the patients to assess their symptoms themselves, demonstrated that dutasteride was more effective compared with finasteride for improving the patients' subjective wellbeing and BPH symptoms.

A previous study demonstrated that the normal development of the prostate and the progression of $\mathrm{BPH}$ are inseparable from the role of DHT, which has a high affinity for the androgen receptor and an inhibitory effect on testosterone (6). The catalytic enzyme that converts testosterone to DHT is 5AR, and 5ARIs inhibit the increase of the PV by suppressing the generation of DHT (30). A previous study found that dutasteride was 45-fold more effective in inhibiting type $15 \mathrm{AR}$ and 2.5-fold more effective in inhibiting type 2 5AR compared with finasteride (31). In addition, one RCT (18) demonstrated that the percent changes in DHT from baseline achieved with $0.5 \mathrm{mg}$ dutasteride $(94.7 \%)$ were significantly greater compared with those obtained with $5 \mathrm{mg}$ finasteride $(70.8 \%)$ after a 24 -week treatment. Therefore, dutasteride offered a significant improvement in patients with LUTS compared with finasteride. However, measurement of IPSS requires the subjective perception of the participants and the values are easily affected by subjective factors. If patients are aware of undergoing experimental treatment, they may be more vigorous regarding their symptoms; further randomized controlled double-blinded studies are required to clarify the changes in IPSS.

A total of five RCTs containing PSA data demonstrated that dutasteride was more effective compared with finasteride in reducing the serum level of PSA. 5ARI may induce the degradation of prostate tissue, which is a source of serum PSA, and the inhibition of DHT may indirectly decrease the level of serum PSA (32). PSA is a commonly used screening indicator for the diagnosis of prostate cancer (PC) (33). Long-term use of 5ARI may lead to low PSA levels, which may reduce the detection rate of PC and increase the rate of misdiagnosis (34). The results of the present study indicated that compared with finasteride, dutasteride may reduce the diagnostic efficacy of PSA in PC to a greater extent. If PSA changes in patients being screened for PC during treatment with dutasterid, further examination may be required for patients being screened for PC. Andriole et al (35) reported that patients exhibited a $>40 \%$ decrease of PSA after 6-month treatment with dutasteride, which may indicate a low risk for PC and re-biopsy may be required.

The safety assessment of the studies included in the present analysis suggested that dutasteride and finasteride were well-tolerated. Regarding the adverse reactions assessed, including any AE, decreased libido and impotence, the dutasteride group exhibited no significant differences compared with the finasteride group. Traish et al (36) suggested that long-term dutasteride therapy led to deterioration of erectile dysfunction, reduced testosterone levels and increased glucose and glycated hemoglobin and changed lipid profiles, suggesting an imbalance of metabolic function and deterioration of gonadal function. It is strongly recommended that the physician explains the potential serious side effects of long-term 5ARI treatment to the patient prior to adopting this treatment.

The limitations of the present meta-analysis require to be acknowledged. The quality of the selected studies was flawed, primarily in terms of study design, patient selection, blinding and outcome data. Therefore, the results of the present meta-analysis should be interpreted with caution. However, the publications included in the present study were all RCTs, which reinforced the results. Bias regarding selection and subjective factors may also affect the final results of the present study. More high-quality RCTs with sufficient sample sizes and statistics are required to confirm the efficacy of dutasteride and finasteride in treating BPH.

The present meta-analysis demonstrated that dutasteride exhibited a greater decrease in IPSS and PSA in the treatment of $\mathrm{BPH}$ compared with finasteride, whereas no significant differences were observed in PV, Qmax and PVRV. The two drugs appeared to exhibit similar rates of adverse reactions. In contrast to finasteride, dutasteride offered a significant improvement in patients with LUTS; however, long-term use of dutasteride may result in low PSA levels, which may lead to a significant reduction in the relevance ratio of PSA regarding PC.

\section{Acknowledgements}

Not applicable.

\section{Funding}

This work was supported by the National Nature Science Foundation of China (grant nos. 81572835, 81801429 and 81870525); Shandong Key Research and Development Program (grant no. 2018GSF118118); and the Natural Science Foundation of Shandong Province (grant no. ZR2017LH016).

\section{Availability of data and materials}

The datasets used and/or analysed during the current study are available from the corresponding author on reasonable request.

\section{Authors' contributions}

HJ made substantial contributions to research concept, screening process, identification of eligible studies and manuscript 
preparation. $\mathrm{ZZ}$ and $\mathrm{YC}$ performed data analysis and prepared the manuscript. JW screened, identified eligible studies and analyzed the data. ZZ, YC and JW performed the data extraction and quality evaluation. HJ conceived the research study and supervised the other authors to ensure integrity of the analysis. All authors reviewed, read and approved the final version of the manuscript.

\section{Ethics approval and consent to participate}

Not applicable.

\section{Patient consent for publication}

Not applicable.

\section{Competing interests}

The authors declare that they have no competing interests.

\section{References}

1. Guess HA, Arrighi HM, Metter EJ and Fozard JL: Cumulative prevalence of prostatism matches the autopsy prevalence of benign prostatic hyperplasia. Prostate 17: 241-246, 1990.

2. Lepor H, Williford W, Barry M, Haakenson C and Jones K: The impact of medical therapy on bother due to symptoms, quality of life and global outcome, and factors predicting response. J Urol 160 1358-1367, 1998

3. AUAPractice Guidelines Committee.AUA guideline on management of benign prostatic hyperplasia (2003). Chapter 1: Diagnosis and treatment recommendations. J Urol 170: 530-547, 2003.

4. Anderson JB, Roehrborn CG, Schalken JA and Emberton M: The progression of benign prostatic hyperplasia: Examining the evidence and determining the risk. Eur Urol 39: 390-399, 2001.

5. Roehrborn CG, McConnell JD, Lieber M, Kaplan S, Geller J, Malek GH, Castellanos R, Coffield S, Saltzman B, Resnick M, et al Serum prostate-specific antigen concentration is a powerful predictor of acute urinary retention and need for surgery in men with clinical benign prostatic hyperplasia. PLESS Study Group Urology 53: 473-480, 1999.

6. Deslypere JP, Young M, Wilson JD and McPhaul MJ: Testosteronem and 5 alpha-dihydrotestosterone interact differently with the androgen receptor to enhance transcription of the MMTV-CAT reporter gene. Mol Cell Endocrinol 88: 15-22, 1992.

7. Welén K and Damber JE: Prostate diseases-role of sex steroids and their inhibitors. Best Pract Res Clin Endocrinol Metab 25: 355-367, 2011.

8. Griffiths K, Eaton CL, Harper ME, Peeling B and Davies P: Steroid hormones and the pathogenesis of benign prostatic hyperplasia. Eur Urol 20 (Suppl 1): S68-S77, 1991.

9. Naslund M, Regan TS, Ong C and Hogue SL: 5-Alpha reductase inhibitors in men with an enlarged prostate: An evaluation of outcomes and therapeutic alternatives. Am J Manag Care 14 (5 Suppl 2): S148-S153, 2008.

10. McConnell JD, Bruskewitz R, Walsh P, Andriole G, Lieber M, Holtgrewe HL, Albertsen P, Roehrborn CG, Nickel JC, Wang DZ, et al: The effect of finasteride on the risk of acute urinary retention and the need for surgical treatment among men with benign prostatic hyperplasia. Finasteride Long-Term Efficacy and Safety Study Group. N Engl J Med 338: 557-563, 1998.

11. Roehrborn CG, Boyle P, Nickel JC, Hoefner K and Andriole G; ARIA3001 ARIA3002 and ARIA3003 Study Investigators: Efficacy and safety of a dual inhibitor of 5-alpha-reductase types 1 and 2 (dutasteride) in men with benign prostatic hyperplasia. Urology 60: 434-441, 2002.

12. Yin T, Qiao Z, Li Y, Li D, Jiang M, An C, Wang F, Zuo M, Hu K and $\mathrm{Li}$ Q: Comparisons of the efficacy and safety of finasteride and dutasteride for benign prostatic hyperplasia: A network meta-analysis. Am J Ther 24: e517-e523, 2017.

13. Jun JEJ, Kinkade A, Tung ACH and Tejani AM: $5 \alpha$-reductase inhibitors for treatment of benign prostatic hyperplasia: A systematic review and meta-analysis. Can J Hosp Pharm 70: 113-119, 2017.
14. Moher D, Liberati A, Tetzlaff J and Altman DG; PRISMA Group: Preferred reporting items for systematic reviews and meta-analyses: The PRISMA statement. Ann Intern Med 151: 264-269, 2009.

15. Jadad AR: Randomised controlled trials: A user's guide. BMJ Publishing Group, London, 1998.

16. Higgins JP and Green S (eds): Cochrane handbook for systematic reviews of interventions. Version 5.1.0. The Cochrane Collaboration, 2011. www.cochrane-handbook.org. Updated March 2011.

17. DerSimonian R and Laird N: Meta-analysis in clinical trials. Control Clin Trials 7: 177-188, 1986.

18. Clark RV, Hermann DJ, Cunningham GR, Wilson TH, Morrill BB and Hobbs S: Marked suppression of dihydrotestosterone in men with benign prostatic hyperplasia by dutasteride, a dual 5alpha-reductase inhibitor. J Clin Endocrinol Metab 89: 2179-2184, 2004.

19. Mohanty NK, Singh UP, Sharma NK, Arora RP and Amitabh V: A comparative study of fixed dose of tamsulosin with finasteride vs tamsulosin with dutasteride in the management of benign prostatic hyperplasia. Indian J Urol 22: 130-134, 2006.

20. Jeong YB, Kwon KS, Kim SD and Kim HJ: Effect of discontinuation of 5alpha-reductase inhibitors on prostate volume and symptoms in men with BPH: A prospective study. Urology 73: 802-806, 2009.

21. Nickel JC, Gilling P, Tammela TL, Morrill B, Wilson TH and RittmasterRS: Comparison of dutasteride and finasteride for treating benign prostatic hyperplasia: The Enlarged Prostate International Comparator Study (EPICS). BJU Int 108: 388-394, 2011.

22. Li Y and Wang J: Clinical efficacy and safety analysis of dutasteride in treatment of benign prostatic hyperplasia. Chinese $\mathrm{J}$ Androl 27: 49-55, 2013.

23. Qian X, Yu G, Qian Y, Xu D, Liu H, Kong X, Zhu Y, Wang Z, Zheng J and Qi J: Efficacy of $5 \alpha$-reductase inhibitors for patients with large benign prostatic hyperplasia $(>80 \mathrm{ml})$ after transurethral resection of the prostate. Aging Male 18: 238-243, 2015.

24. Girman CJ: Population-based studies of the epidemiology of benign prostatic hyperplasia. Br J Urol 82 (Suppl 1): S34-S43, 1998.

25. Emberton M, Andriole GL, de la Rosette J, Djavan B, Hoefner K, Vela Navarrete R, Nordling J, Roehrborn C, Schulman C, Teillac P, et al: Benign prostatic hyperplasia: A progressive disease of aging men. Urology 61: 267-273, 2003.

26. Jacobsen SJ, Jacobson DJ, Girman CJ, Roberts RO, Rhodes T, Guess HA and Lieber MM: Natural history of prostatism: Risk factors for acute urinary retention. J Urol 158: 481-487, 1997.

27. Corona G, Vignozzi L, Rastrelli G, Lotti F, Cipriani S and Maggi M: Benign prostatic hyperplasia: A new metabolic disease of the aging male and its correlation with sexual dysfunctions. Int J Endocrinol 2014: 329456, 2014.

28. O'Leary MP, Roehrborn CG and Black L. Dutasteride significantly improves quality of life measures in patients with enlarged prostate. Prostate Cancer Prostatic Dis 11: 129-133, 2008.

29. Corona G, Tirabassi G, Santi D, Maseroli E, Gacci M, Dicuio M, Sforza A, Mannucci E and Maggi M: Sexual dysfunction in subjects treated with inhibitors of $5 \alpha$-reductase for benign prostatic hyperplasia: A comprehensive review and meta-analysis. Andrology 5: 671-678, 2017

30. Shibata Y, Arai S, Miyazawa Y, Shuto T, Nomura M, Sekine Y, Koike H, Matsui H, Ito K and Suzuki K: Effects of steroidal antiandrogen or 5-alpha-reductase inhibitor on prostate tissue hormone content. Prostate 77: 672-680, 2017.

31. Evans HC and Goa KL: Dutasteride. Drugs Aging 20: 905-918, 2003.

32. Guess HA, Gromley GJ, Stoner E and Oesterling JE: The effect of finasteride on prostate specific antigen: Review of available data. J Urol 155: 3-9, 1996.

33. Schröder FH: Review of diagnostic markers for prostate cancer. Recent Results Cancer Res 181: 173-182, 2009.

34. Morgia G, Urzì D and Russo GI: 5ARI and PSA: Evidences. Urologia 81 (Suppl 24): S4-S11, 2014 (In Italian).

35. Andriole GL, Bostwick D, Brawley OW, Gomella L, Marberger M, Montorsi F, Pettaway C, Tammela TL, Teloken C, Tindall D, et al: The effect of dutasteride on the usefulness of prostate specific antigen for the diagnosis of high grade and clinically relevant prostate cancer in men with a previous negative biopsy: Results from the REDUCE study. J Urol 185: 126-131, 2011.

36. Traish A, Haider KS, Doros G and Haider A: Long-term dutasteride therapy in men with benign prostatic hyperplasia alters glucose and lipid profiles and increases severity of erectile dysfunction. Horm Mol Biol Clin Investig 30, 2017.

This work is licensed under a Creative Commons Attribution-NonCommercial-NoDerivatives 4.0 International (CC BY-NC-ND 4.0) License. 